\title{
Active immunization against melatonin in Ile-de-France ewes and photoperiodic control of prolactin secretion and ovulatory activity
}

\author{
A. Daveau ${ }^{1}$, B. Malpaux ${ }^{1}$, Y. Tillet ${ }^{1}$, G. Roblot ${ }^{2}$, R. Wylde ${ }^{2}$ and \\ P. Chemineau ${ }^{1 *}$ \\ ${ }^{1}$ INRA Unité de Neuroendocrinologie Sexuelle, Station de Physiologie de la Reproduction, 37380 Nouzilly, \\ France; and ${ }^{2}$ Laboratoire de Chimie et Pharmacologie 15 av Ch Flahaut, 34060 Montpellier, cédex 1, \\ France
}

\begin{abstract}
An experiment was conducted to determine whether active immunization against melatonin could modify the perception of abrupt photoperiodic changes in ewes. Two groups each containing six intact Ile-de-France ewes were submitted to alternate periods of short days for 2.5 months and long days for 2.5 days for about 70 weeks. Three series of active immunizations against a melatonin conjugate were carried out during the first of the three long-day periods. Control ewes were actively immunized at the same time against human serum albumin. Blood samples were taken once a week throughout the experiment to measure antibody titre and affinity, and prolactin and progesterone concentrations. Sera of all treated ewes demonstrated higher antibody titres than those of control ewes. Antisera were highly specific, as evidenced by the absence of displacement of iodinated melatonin in the presence of ten melatonin metabolites. Significant effects of photoperiod and of the interaction between treatment and photoperiod on prolactin concentration were detected. Prolactin concentrations in plasma of the control ewes were high during long days and low during short days. However, in the treated ewes, with the exception of the first period of long days, prolactin concentrations were not influenced by photoperiodic changes. Ovulatory activity of control ewes, as demonstrated by progesterone measurements, was stimulated by short days and inhibited by long days. In contrast, ovulatory activity of treated ewes, after a response identical to that of control ewes after the first photoperiodic shift from long to short days, showed a complete desynchronization of ovulatory activity relative to photoperiodic changes. Immunization against melatonin can therefore modify the influence of artificial photoperiodic changes on prolactin secretion and ovulatory activity in ewes.
\end{abstract}

\section{Introduction}

Photoperiod is the environmental cue used by temperate breeds of sheep to regulate their reproductive seasonality (Ortavant et al., 1985). Pinealectomy abolishes the reproductive responses of ewes to photoperiodic changes (Bittman et al., 1983a). Melatonin, an indoleamine, synthesized and secreted by the pineal gland into the general circulation, mediates the photoperiodic drive of reproductive activity (Karsch et al., 1984). In pinealectomized ewes, long periods of infusion of melatonin $\left(16 \mathrm{~h} \mathrm{day}^{-1}\right)$ mimic short daylength and stimulate reproductive activity; in contrast, short periods of infusion $(8 \mathrm{~h}$ day ${ }^{-1}$ ) mimic long daylength and inhibit reproductive activity (Bittman et al., 1983b, 1985). Discrete photoperiodic signals, provided by melatonin infusions to pinealectomized ewes, can synchronize the circannual rhythm of LH neuroendocrine

*Correspondence.

Received 24 February 1994. activity (Woodfill et al., 1991). Consequently, if adequate replacement therapies, using melatonin alone in pinealectomized ewes, can completely restore the effects of photoperiodic changes observed in intact ewes, it is possible that under normal conditions, melatonin is the major hormone responsible for the reproductive response of ewes to changes in daylength.

However, the few experiments involving the immunization of sheep against melatonin under natural conditions gave conflicting results in comparison with pinealectomized, melatonin-treated animals. Under such conditions of immunization, ewes (Arendt et al., 1981) and rams (Lincoln and Almeida, 1981) did not show clear-cut changes in their reproductive seasonality.

It is, therefore, of interest to determine whether, in intact ewes, immunoneutralization of melatonin modifies the prolactin response to artificial rather than natural daylength changes, and the ovulatory response to artificial changes in photoperiod. The present experiment was therefore conducted to test 


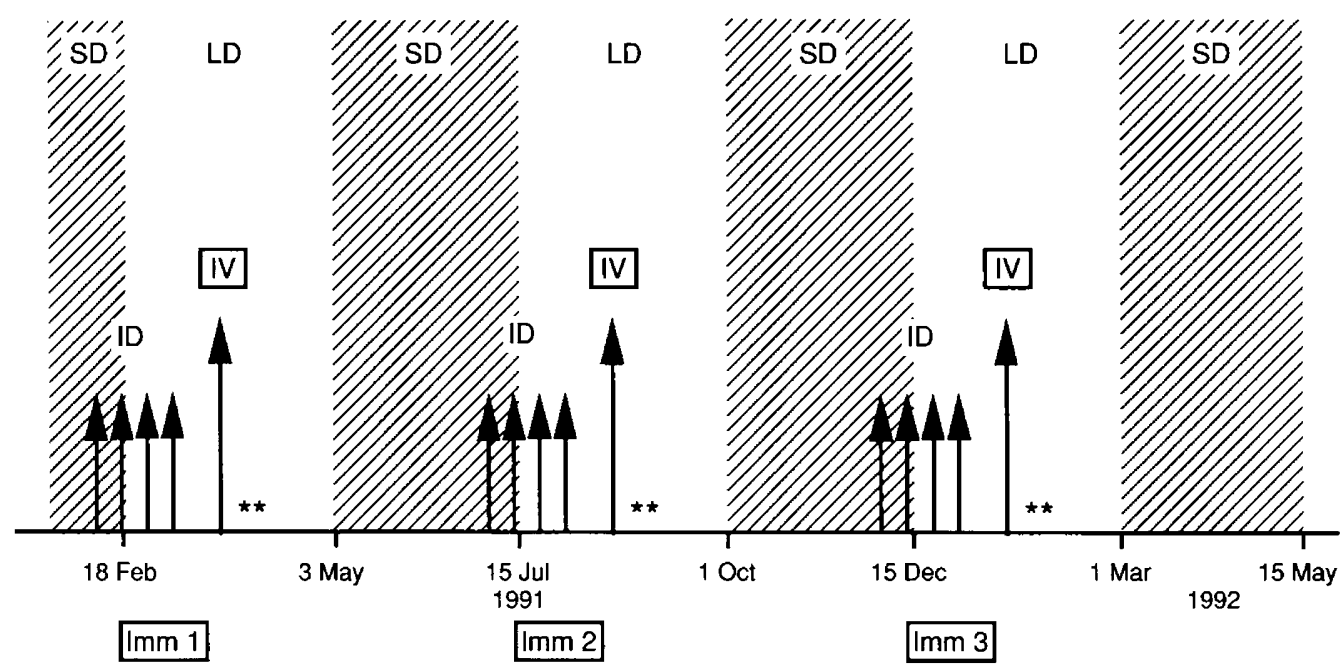

Fig. 1. Experimental design. Ile-de-France ewes were submitted to alternate periods of 2.5 months of short days (SD, hatched areas) and 2.5 months of long days ( $\mathrm{LD}$, white areas), and received three series of immunizations (Imm 1, 2 and 3), each one consisting of four intradermal injections (ID) followed by one intravenous injection (IV). Characterization of antibody was carried out in blood samples obtained twice a month and 5-7 days after IV $\left({ }^{* *}\right)$.

the working hypothesis that active immunization against melatonin modifies the effects of abrupt photoperiodic changes on prolactin secretion and ovulatory activity.

A preliminary report of the work was presented at the Sixth Colloquium of the European Pineal Society in Copenhagen in July 1993.

\section{Materials and Methods}

Two groups, each containing six intact adult Ile-de-France ewes (Ovis aries L.), were submitted to alternating periods of 2.5 months of short days ( $8 \mathrm{~h}$ light: $16 \mathrm{~h}$ dark) and long days ( $16 \mathrm{~h}$ light: $8 \mathrm{~h}$ dark). Photoperiodic treatment began on 23 January 1991 and ended on 30 June 1992 (Fig. 1). The two groups of ewes were separated and maintained in two rooms in a light-proof building where ambient temperature changes were identical from one room to another and followed an attenuated seasonal trend linked to climatological conditions. Daylength was regulated by electronic timers that operated fluorescent bulbs providing approximately 300 lux at the level of the animals' eyes. Ewes were fed daily with hay, straw and corn. They had free access to water and mineral licks. All manipulations of ewes were performed in accordance with UK legal requirements.

Three series of active immunizations against a melatonin conjugate or against human serum albumin were carried out at about the times of transition from short days to long days. Melatonin (Aldrich Chimie, Ilkirch) was coupled to HSA (Aldrich Chimie) by glutaraldehyde (Aldrich Chimie) as described by Tillet et al. (1986). Each series of immunizations comprised four intradermal injections of the immunogen at weekly intervals, followed by one i.v. injection of the immunogen a month later. The first intradermal injection was given with complete Freund's adjuvant and the second and third injection with incomplete Freund's adjuvant. The i.v. injection was given without adjuvant. This procedure, which uses a repetition of the primary immunization instead of a single booster immunization, has already been used in sheep with satisfactory results (Tillet $e$ al., 1986). Blood samples for characterization of antibody were collected 5-7 days after the i.v. injection. Antisera were characterized by radioimmunoassay using ${ }^{125}$ I-labelled melatonin (specific activity $2 \times 10^{-3} \mathrm{Ci} \mathrm{mmol}^{-1}$; Amersham, Paris). Antibody titre was defined as the antisera dilution that binds $50 \%$ of the tracer (in all assays $100 \mu \mathrm{l}$ samples were incubated with 15300 d.p.m. ${ }^{125}$ I-labelled melatonin).

Specificity of antisera was characterized by using the displacement of ${ }^{125}$ I-labelled melatonin in the presence of ten melatonin metabolites, tested in the sera of two representative ewes taken after the third immunization period.

Blood samples were taken once a week throughout the experiment, and always at the same hour relative to lights on. They were obtained by venepuncture of the jugular vein; plasma and serum were separated and stored at $-20^{\circ} \mathrm{C}$ until assayed. Samples taken twice a month were used to measure antibody titre in the serum; samples taken once a week were used for assays of prolactin and progesterone concentrations in the plasma.

Prolactin was assayed in duplicate $10-50 \mu \mathrm{l}$ aliquots of plasma using the radioimmunoassay method of Kann (1971). Sensitivity was $8 \mathrm{ng} \mathrm{ml}^{-1}$ of plasma of NIDDK-o-prolactin-19 for $50 \mu \mathrm{l}$. Intra-assay coefficient of variation for two plasma pools averaged $11 \%$. All samples were measured in the same assay.

Progesterone was assayed in duplicate by the method described by Saumande et al. (1985), slightly modified as follows: immunoprecipitation was accelerated by adding polyethylene glycol and the second antibody at the same time. All tubes were measured in the same assay. Sensitivity was $0.1 \mathrm{ng} \mathrm{ml}^{-1}$ and the intra-assay coefficients of variation for $1.8 \mathrm{ng} \mathrm{ml}^{-1}$ and $5.6 \mathrm{ng} \mathrm{ml}^{-1}$ plasma were $4.1 \%$ and $14.7 \%$, 

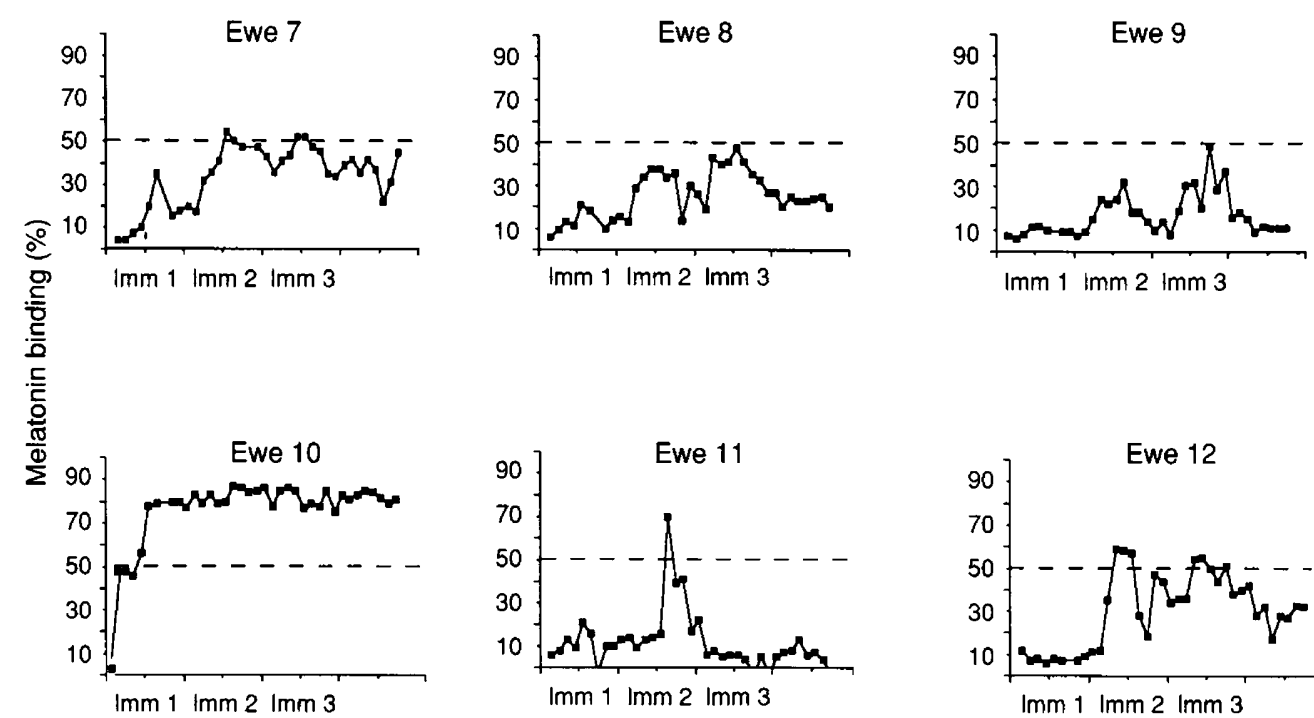

Fig. 2. Melatonin binding (percentage binding of ${ }^{125}$ I-labelled melatonin at a dilution $1 / 10000$ ) determined in the serum of blood samples taken twice a month from six Ile-de-France ewes that had received three series of immunizations (Imm 1, 2 and 3) against a melatonin conjugate coupled to human serum albumin.

respectively. A plasma progesterone concentration higher than $1 \mathrm{ng} \mathrm{ml} \mathrm{m}^{-1}$ in the blood sample taken once a week was considered to indicate the presence of an active corpus luteum and was used to estimate the date of ovulation, which was arbitrarily defined as 3 days before the first increase in plasma progesterone concentration above $1 \mathrm{ng} \mathrm{ml} \mathrm{ml}^{-1}$ (Thimonier, 1978).

\section{Statistical analysis}

Statistical analysis was performed by repeated measures analysis of variance, after a logarithmic transformation of prolactin data and testing the effects of immunization treatment, photoperiod and time. In such a model, significant interaction between treatment and photoperiod indicated that prolactin concentrations varied with photoperiod in a different manner between groups. It was followed by Duncan's new multiple range test for differences between treatment groups. All statistical analyses were carried out by means of Superanova program (Abacus Concepts, Berkeley, CA).

\section{Results}

\section{Titres and specificity of the antisera}

Antibody titres of sera of all ewes immunized against melatonin (MI) were higher than $1 / 5000$ at the third immunization, in contrast to ewes immunized against human serum albumin (HSA). Four MI ewes had a titre between $1 / 16000$ and $1 / 32000$ and one ewe a titre higher than $1 / 32000$ at the time of the second immunization.

Variations in the titres, which were monitored throughout the experiment from the samples taken twice a month, at a dilution of $1 / 10000$ (Fig. 2), confirmed the preceding results and showed that in two ewes (Nos 9 and II) melatonin binding decreased almost to zero between the immunization periods; in ewes 7,8 and 12 melatonin binding was intermediate between the immunization periods, and ewe $10 \mathrm{had}$ an antisera titre which remained high between the immunization periods.

Antisera were highly specific, as evidenced by the absence of displacement of ${ }^{125}$ I-labelled melatonin in the presence of ten melatonin-related compounds (serotonin, $\mathrm{N}$-acetylserotonin, tryptamine, 5-methoxytryptamine, 6-hydroxymelatonin, tryptophol, 5-methoxytryptophol, tryptophan, 5-hydroxytryptophan and 5-hydroxyindol acetic acid) tested in the sera of two representative ewes (Nos 10 and 12) taken after the third immunization period.

\section{Prolactin}

Significant effects of photoperiod and of the interaction between treatment and photoperiod on prolactin concentration were detected $(P=0.0016$ and $P=0.0362$, respectively). The effect of treatment was not significant.

Prolactin concentrations in the plasma of the HSA ewes were high during long days and low during short days (Figs 3 and 4). In contrast, in the MI ewes, with the exception of the first period of long days (when antibody titres were not yet high), prolactin concentrations were not influenced by photoperiodic changes (HSA ewes: short days: 35,59 and 49 versus long days: 158,143 and $103 \mathrm{ng} \mathrm{ml}{ }^{-1}$, compared with MI ewes: short days: 62,67 and 66 versus long days: 125,85 and $66 \mathrm{ng} \mathrm{ml}^{-1}$ ). Prolactin concentrations were significantly modified in MI ewes during the first period of long days at the end of which time prolactin concentrations fell markedly (the interaction between time and treatment and the difference with the HSA ewes were significant). This indicates that the prolactin response of the Ml ewes to photoperiod was modified as early as the first immunization, at a time when the antisera titre are still relatively low (Figs 3 and 4). 
(a)

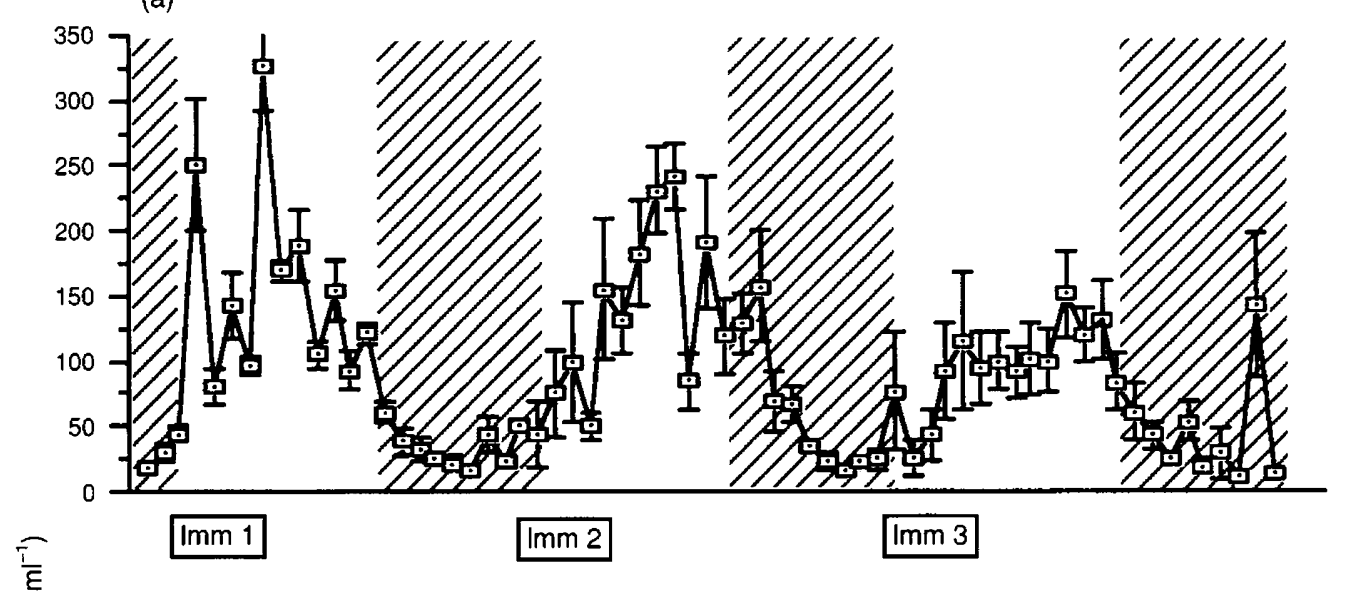

(b)

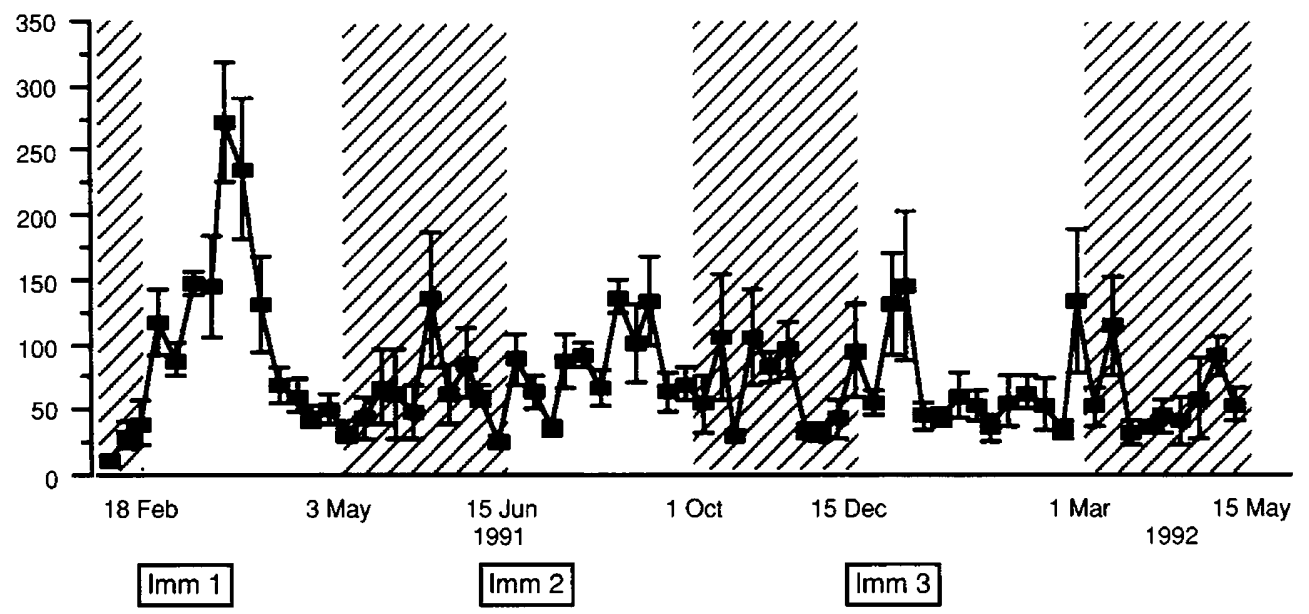

Fig. 3. Weekly plasma prolactin concentrations (mean \pm SEM) from two groups of six intact Ile-de-France ewes each of which had received three series of immunizations (Imm 1, 2 and 3) against (a) human serum albumin or (b) melatonin. (可) Short days; ( $\square$ ) long days.

\section{Progesterone concentration in relation to ovulatory activity}

Progesterone measurements, which allow the estimation of dates of ovulations, demonstrated that the ovulatory activity of HSA ewes was stimulated by short days (interval between the change from long days to short days and first ovulation, mean \pm SEM, $49.0 \pm 3.1,59.8 \pm 6.3$ and $52.5 \pm 1.6$ days, for the three photoperiodic cycles) and inhibited by long days, leading to a consistent duration of ovulatory activity $(53.5 \pm 7.1$ and $41.5 \pm 10.8$ days), and high synchrony between ewes (Figs 5 and 6).

In contrast, ovulatory activity of $\mathrm{MI}$ ewes, after a response close to that of HSA ewes after the first change from long days to short days (interval to first ovulation $40.8 \pm 8.6$ days), showed a complete desynchronization of ovulatory activity relative to changes in photoperiod. One ewe was always cyclic, while others showed irregular alternations between activity and rest independent of the changes in the photoperiodic signal, making it difficult to distinguish periods of ovulatory cyclicity from periods of anovulation clearly (Figs 5 and 6).

The frequency of ovulatory cycles per week and per group (Fig. 5) showed that the ovulatory activity of females in the HSA group was influenced by alternation between long and short days, while MI ewes demonstrated erratic ovulatory activity after the first period of long and short days.

\section{Discussion}

In the study described here, active immunization against conjugated melatonin resulted in the development of high antibody titres in treated ewes, which were in the range of, or higher than, values previously reported. The large variability between ewes has frequently been reported in immunization studies (sheep: Arendt et al., 1981; Lincoln and Almeida, 1981; Foldes et al., 1983; goats: Foldes et al., 1992; deer: Ataja et al., 1990). 

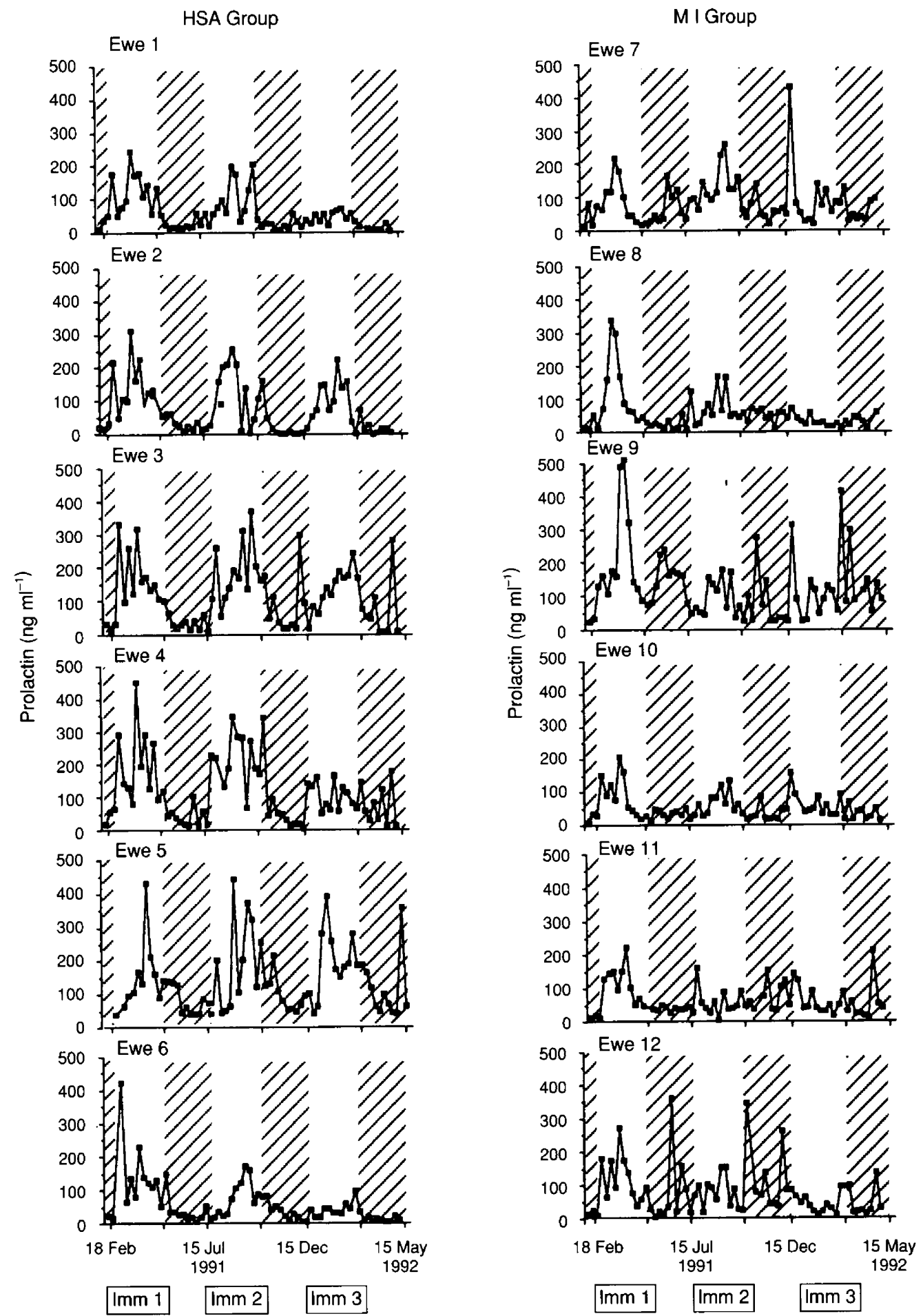

Fig. 4. Individual plasma prolactin concentrations from two groups of six intact Ile-de-France ewes each of which had received three series of immunizations (Imm 1, 2 and 3) against melatonin (MI group) or human serum albumin (HSA group). ( $(\nabla)$ Short days; ( $\square$ ) long days.

The high titres obtained in all Ml ewes after the second and third immunization and the specificity of the antibodies demonstrate the efficiency of the melatonin conjugate used here in producing antibodies that immunoneutralize melatonin in the blood circulation.
However, in contrast to these previous reports, the MI ewes in the study reported here lost their ability to respond to photoperiodic changes.

Plasma prolactin concentrations of the $\mathrm{MI}$ ewes clearly indicate that this hormonal secretion did not respond to the 


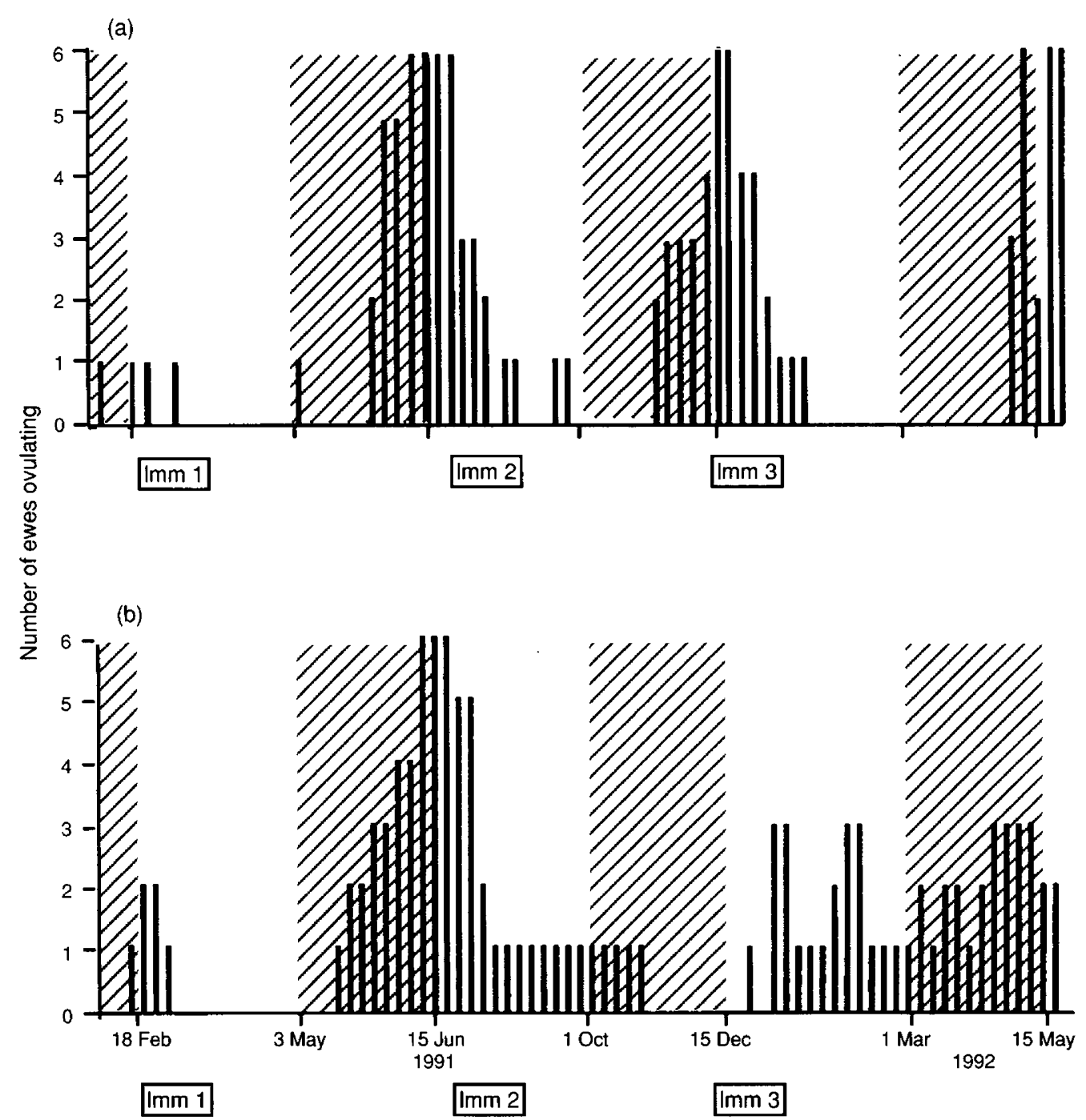

Fig. 5. Number of cyclic ewes ovulating per week in two groups of six Ile-de-France ewes each of which had received three series of immunizations (Imm 1, 2 and 3) against (a) human serum albumin or (b) melatonin. (四) Short days; ( $\square$ ) long days.

abrupt light changes to which the animals were exposed. There have been reports concerning immunization against melatonin and prolactin secretion. In rats, immunization against melatonin caused a significant reduction in prolactin values, although the diurnal rhythm persisted (Niles et al., 1977). In ewes, prolactin concentrations remained unaffected (Arendt $e t$ al., 1981), and in red deer, prolactin plasma concentrations were increased (Ataja et al., 1990). We conclude that the MI ewes could no longer respond to the photoperiodic changes to which they were submitted.

In HSA ewes, the ovulatory activity was influenced by the photoperiodic shifts as described by Karsch et al. (1984) and Ravault and Thimonier (1988), while the MI ewes demonstrated erratic variations in ovulations after the first short-day period. Reproductive activity in MI ewes was no longer influenced by photoperiod; this is in contrast to previous findings. As mentioned above, immunized ewes (Arendt et al., 1981) and rams (Lincoln and Almeida, 1981) maintained under a natural photoperiod, did not show clear-cut changes in reproductive seasonality. The photoperiodic conditions of our experiment (artificial abrupt changes between long days and short days) compared with the conditions described in the other reports (natural daylength), are probably responsible for the observed discrepancy between the results. Under conditions of natural daylength, the absence of a response to melatonin immunization could be attributed to the fact that, in the absence of a perception of photoperiodic changes, these animals were exposed to other environmental cues (temperature, social cues from other animals) to time their breeding season in the year. In the present study, these cues were either completely absent (social contact with control ewes), or attenuated (temperature) as animals were maintained in two separate rooms under attenuated ambient temperature changes.

Although the pineal gland of sheep is located deep in the brain, it is situated outside of the blood-brain barrier, and secretes melatonin via the Galen vein into the general circulation. It is likely that the immunoneutralization of melatonin took place in the general blood circulation as the 
HSA Group

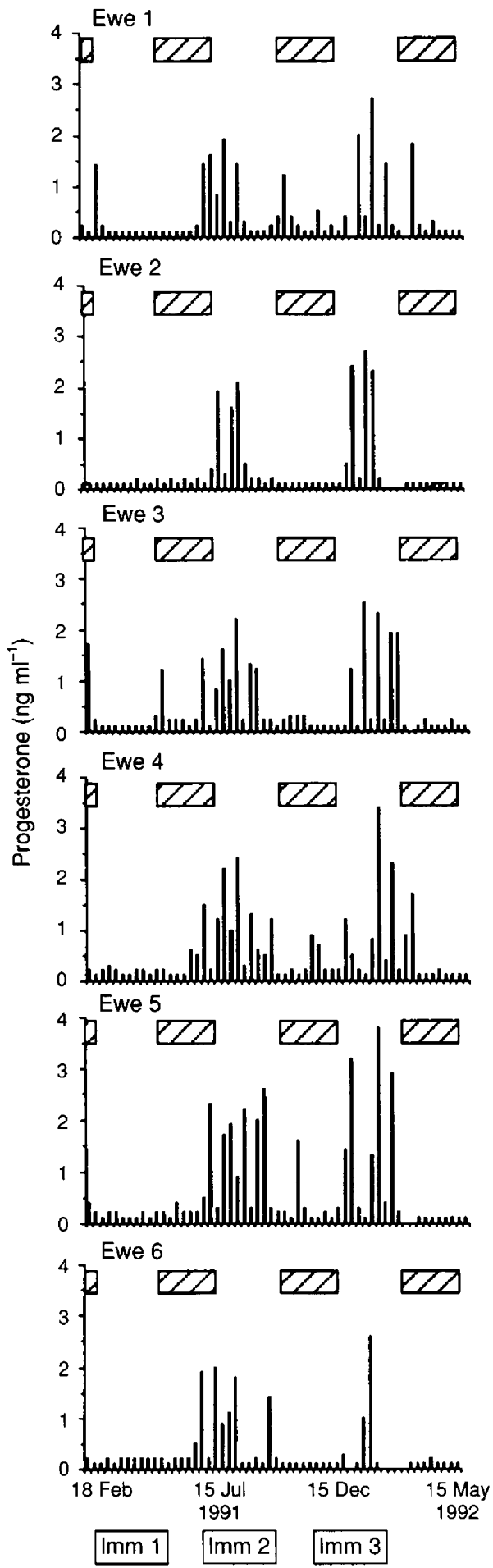

M I Group

Ewe 7

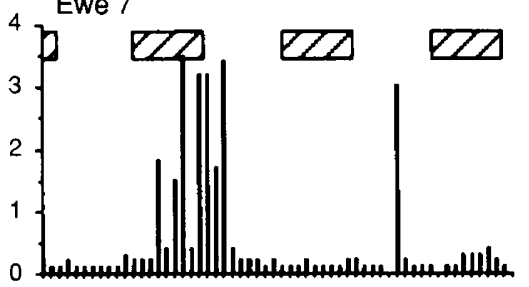

Ewe 8
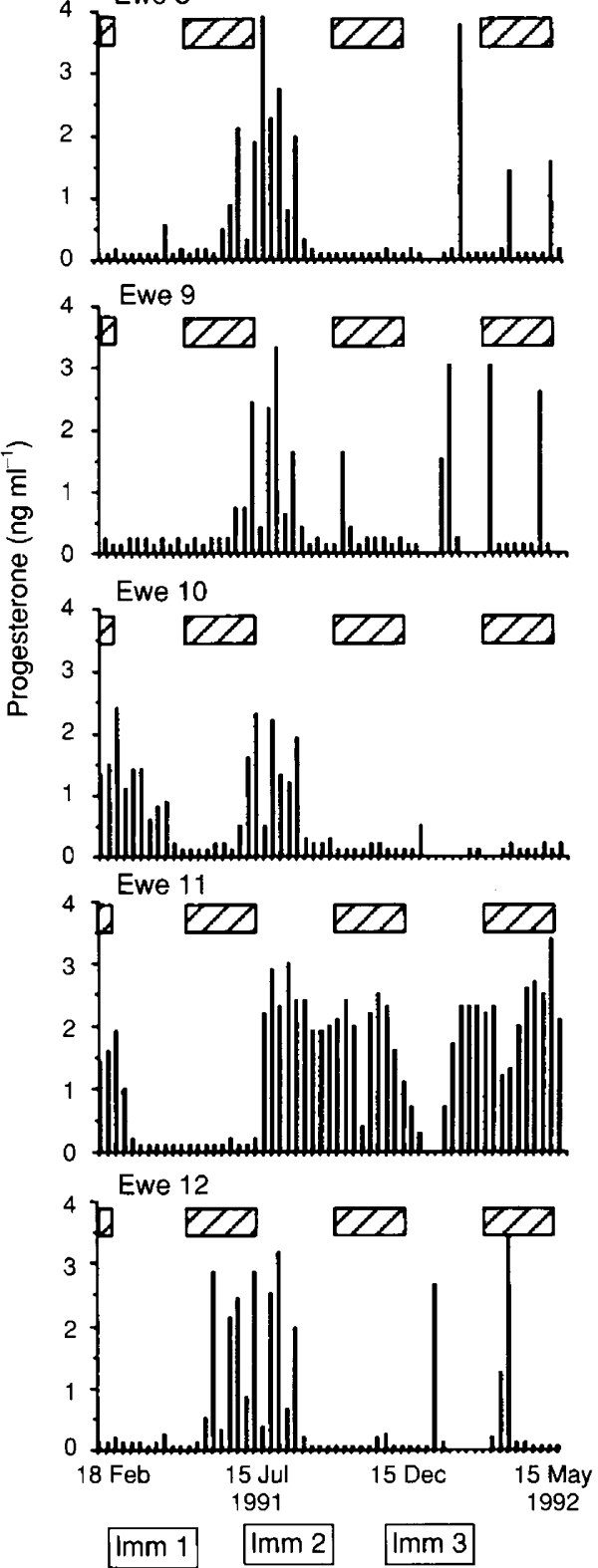

Fig. 6. Individual plasma progesterone concentrations in two groups of six intact Ile-de-France ewes each of which had received three series of immunizations (Imm 1, 2 and 3) against melatonin (MI group) or human serum albumin (HSA group). (包) Short days.

immunoglobulin probably did not cross the blood-brain barrier. Such a suggestion is consistent with the fact that the restoration of blood melatonin concentrations to night-time values by subcutaneous delivery of melatonin caused the same effects as exposure to short days (Bittman et al., 1985). However, the results presented here do not distinguish between the parts of the ewe brain (in particular between the pars tuberalis (Williams and Helliwell, 1993) and the 
mediobasal hypothalamus (Malpaux et al., 1993)) where melatonin exerts its control of reproductive activity.

It is possible that the antibodies bind melatonin during the night and liberate it during the day, so that the ewes were in a similar situation to those treated with constant infusions of melatonin, as with a subcutaneous implant.

Whatever the mechanism of action, the results reported here show that in ewes active immunization against melatonin can modify the perception of artificial photoperiodic changes.

The authors thank J. Pelletier for his help during the course of the study and P. Lonergan for help with the English version of this manuscript. This work was supported in part by a grant from 'Région Centre'.

\section{References}

Arendt J, Symons AM and Laud C (1981) Pineal function and photoperiod in the ewe Les Colloques de l'INRA 6 219-229

Ataja AM, Wilson PR, Hodgson J, Hoskinson RW, Purchas RW, Varela-Alvarez $\mathbf{H}$ and Barry TN (1990) Responses in venison production to grazing pastures based upon perennial ryegrass or annual ryegrass and to immunisation against melatonin Proceedings New Zealand Society of Animal Production 50 279-285

Bittman EL, Karsch FJ and Hopkins JN (1983a) Role of the pineal gland in ovine photoperiodism: regulation of seasonal breeding and the negative feedback effects of estradiol upon luteinizing hormone secretion Endocrinology 113 329-336

Bittman EL, Dempsey RJ and Karsch FJ (1983b) Pineal melatonin secretion drives the reproductive response to daylength in the ewe Endocrinology 113 2276-2283

Bittman EL, Kaynard AH, Olster DH, Robinson JE, Yellon SM and Karsch FJ (1985) Pineal melatonin mediates photoperiodic control of pulsatile luteinizing hormone secretion in the ewe Neuroendocrinology 40 409-418

Foldes A, Hoskinson RM, Scaramuzzi RJ, Hinks NT and Maxwell CA (1983) Modification of sheep pineal $\beta$-adrenoreceptors by some gonadal steroids but not by melatonin Neuroendocrinology 37 378-386
Foldes A, Hoskinson RM, Baker P, McDonald BJ, Maxwell CA and Restall BJ (1992) Effect of immunization against melatonin on seasonal fleece growth in feral goats Journal of Pineal Research 13 85-94

Kann G (1971) Dosage radioimmunologique de la prolactine plasmatique chez les ovins Comptes Rendus de l'Académie des Sciences Paris 272 2808-2811

Karsch FJ, Bittman EL, Foster DL, Goodman RL, Legan SJ and Robinson JE (1984) Neuroendocrine basis of seasonal reproduction Recent Progress in Hormone Research 40 185-232

Lincoln G and Almeida OFX (1981) Melatonin and the seasonal photoperiodic response in sheep Les Colloques de l'INRA 6 231-251

Malpaux B, Daveau A, Maurice F, Gayrard V and Thiéry JC (1993) Short day effects of melatonin on LH secretion in the ewe: evidence for central sites of action in the mediobasal hypothalamus Biology of Reproduction 48 752-760

Niles LP, Brown GM and Grota LJ (1977) Effects of neutralization of circulating melatonin and $N$-acetylserotonin on plasma prolactin levels Neuroendocrinology 23 14-22

Ortavant R, Pelletier J, Ravault JP, Thimonier J and Volland-Nail P (1985) Photoperiod: main proximal and distal factor of the circannual cycle of reproduction in farm mammals Oxford Reviews of Reproductive Biology 7 305-345

Ravault JP and Thimonier J (1988) Melatonin patterns in ewes maintained under skeleton or resonance photoperiodic regimens Reproduction, Nutrition, Développement 28 473-486

Saumande J, Tamboura D and Chupin D (1985) Changes in milk and plasma concentrations of progesterone in cows after treatment to induce superovulation and their relationships with number of ovulations and embryos collected Theriogenology 23 719-731

Thimonier J (1978) L'activité ovarienne chez les bovins. Moyens d'étude et facteurs de variation Annales de Médecine Vétérinaire 122 81-92

Tillet Y, Ravault JP, Selve C, Eeving G, Castro B and Dubois MP (1986) Conditions d'utilisation d'anticorps spécifiques pour la visualisation immunohistochimique de la sérotonine et de la mélatonine dans la glande pinéale du mouton Comptes Rendus de l'Académie des Sciences Paris 303 77-82

Williams LM and Helliwell RJA (1993) Melatonin and seasonality in the sheep Animal Reproduction Science 33 159-182

Woodfill CJ, Robinson JE, Malpaux B and Karsch FJ (1991) Synchronization of the circannual reproductive rhythm of the ewe by discrete photoperiodic signals Biology of Reproduction 45 110-121 